\title{
Long-term outcomes of epilepsy surgery in 85 pediatric patients followed up for over 10 years: a retrospective survey
}

\author{
Hiroshi Hosoyama, MD, ${ }^{1,2}$ Kazumi Matsuda, MD, PhD, ${ }^{1}$ Tadahiro Mihara, MD, PhD, ${ }^{1}$ \\ Naotaka Usui, MD, PhD, ${ }^{1}$ Koichi Baba, MD, ${ }^{1}$ Yushi Inoue, MD, PhD, ${ }^{1}$ Takayasu Tottori, MD, PhD, ${ }^{1}$ \\ Toshiaki Otsubo, MD, PhD, ${ }^{3}$ Yumi Kashida, MD, ${ }^{1,2}$ Koji lida, MD, PhD, ${ }^{4}$ Hirofumi Hirano, MD, PhD, ${ }^{2}$ \\ Ryosuke Hanaya, MD, $\mathrm{PhD},{ }^{2}$ and Kazunori Arita, MD, $\mathrm{PhD}^{2}$
}

\begin{abstract}
${ }^{1}$ National Epilepsy Center, Shizuoka Institute of Epilepsy and Neurological Disorders, Shizuoka; ${ }^{2}$ Department of Neurosurgery, Graduate School of Medical and Dental Sciences, Kagoshima University, Kagoshima; ${ }^{3}$ Department of Neurosurgery, Fujimoto General Hospital, Miyakonojo, Miyazaki; and ${ }^{4}$ Department of Neurosurgery, Graduate School of Biomedical Sciences, Hiroshima University, Hiroshima, Japan
\end{abstract}

OBJECTIVE The aim of this study was to investigate the treatment outcomes and social engagement of patients who had undergone pediatric epilepsy surgery more than 10 years earlier.

METHODS Between 1983 and 2005, 110 patients younger than 16 years underwent epilepsy surgery at the National Epilepsy Center, Shizuoka Institute of Epilepsy and Neurological Disorders. The authors sent a questionnaire to 103 patients who had undergone follow-up for more than 10 years after surgery; 85 patients $(82.5 \%)$ responded. The survey contained 4 categories: seizure outcome, use of antiepileptic drugs, social participation, and general satisfaction with the surgical treatment (resection of the epileptic focus, including 4 hemispherectomies). The mean patient age at the time of surgery was $9.8 \pm 4.2(\mathrm{SD})$ years, and the mean duration of postoperative follow-up was $15.4 \pm 5.0$ years. Of the 85 patients, $79(92.9 \%)$ presented with a lesional pathology, such as medial temporal sclerosis, developmental/neoplastic lesions, focal cortical dysplasia, and gliosis in a single lobe.

RESULTS For 65 of the 85 responders (76.5\%), the outcome was recorded as Engel Class I (including 15 [93.8\%] of 16 patients with medial temporal sclerosis, 20 [80.0\%] of 25 with developmental/neoplastic lesions, and 27 [73.0\%] of 37 with focal cortical dysplasia). Of these, 29 (44.6\%) were not taking antiepileptic drugs at the time of our survey, 29 $(44.6 \%)$ held full-time jobs, and 33 of 59 patients (55.9\%) eligible to drive had a driver's license. Among 73 patients who reported their degree of satisfaction, 58 (79.5\%) were very satisfied with the treatment outcome.

CONCLUSIONS The seizure outcome in patients who underwent resective surgery in childhood and underwent followup for more than 10 years was good. Of 85 respondents, 65 (76.5\%) were classified in Engel Class I. The degree of social engagement was relatively high, and the satisfaction level with the treatment outcome was also high. From the perspective of seizure control and social adaptation, resective surgery yielded longitudinal benefits in children with intractable epilepsy, especially those with a lesional pathology in a single lobe.

https://thejns.org/doi/abs/10.3171/2016.12.PEDS16197

KEY WORDS epilepsy surgery; outcome; pediatrics; Engel class; social participation

A MONG children with epilepsy, $10 \%-30 \%$ develop pharmacoresistance. ${ }^{4,17,54,64}$ Recurrent electrophysiological insults from frequent seizures and adverse effects from antiepileptic drugs (AEDs) damage the developing brain, resulting in cognitive dysfunction, difficulties in social adaptation, and a lowering in the patient's quality of life (QOL). ${ }^{15,19,23,36,56,61}$ Adults with epilepsy have been surgically treated for several decades, and the longterm outcomes have tended to be good. ${ }^{45,56,57}$ For decades after surgery, seizures were controlled and the patients' improved QOL was sustained. ${ }^{45}$ Advances in neuroimaging and surgical techniques and in electrophysiological

ABBREVIATIONS AED = antiepileptic drug; $D Q=$ development quotient; $E E G$ = electroencephalography; FCD = focal cortical dysplasia; $M E G=$ magnetoencephalography; MTS = medial temporal sclerosis; $\mathrm{QOL}=$ quality of life.

SUBMITTED April 6, 2016. ACCEPTED December 8, 2016.

INCLUDE WHEN CITING Published online March 3, 2017; DOI: 10.3171/2016.12.PEDS16197. 
analysis have increased the scope of surgical treatment of pediatric patients with epilepsy. $22,47,66$

The detrimental effects of frequent seizures and antiepileptic drugs on the developing brain may result in learning disability, psychiatric manifestations, difficulty with social adaptation, and a poor QOL..$^{13,17}$ Epilepsy surgery in childhood has been reported to improve psychosocial adaptation and the QOL of these patients. ${ }^{26,28,29,34,35,60} \mathrm{Howev-}$ er, despite childhood epilepsy surgery, some patients manifest social maladaptation, resulting in unemployment and psychosocial seclusion in adulthood. Therefore, to better understand the true effect of epilepsy surgery in pediatric patients, the seizure outcome and their social participation in adolescence and adulthood should be investigated. As there are few reports on the long-term effects of pediatric epilepsy surgery, ${ }^{2,20,26}$ we performed a retrospective survey of the seizure status, social engagement, and satisfaction with the outcome of epilepsy surgery of patients who had undergone resective surgery in childhood at least 10 years earlier. We also investigated factors that contributed to their social participation.

\section{Methods}

\section{Study Population}

Between 1983 and 2005, 751 patients underwent epilepsy surgery at the National Epilepsy Center, Shizuoka Institute of Epilepsy and Neurological Disorders in Japan. Of the 751 patients, 110 (14.6\%) were younger than 16 years at the time of surgery. Two years later, 80 of the 110 patients $(72.7 \%)$ were recorded as being in Engel Class I, 10 (9.1\%) in Class II, 4 (3.6\%) in Class III, and 16 (14.5\%) in Class IV.

A second operation was performed in 12 patients
(10.9\%). Of these, 6 were excluded from our study; 5 were older than 16 years at the time of reoperation and the remaining patient had undergone reoperation less than 10 years earlier. The seventh patient who had died of unknown causes was also excluded. A flowchart of our patient selection procedure is presented in Fig. 1. Therefore, we sent our questionnaire to 103 surgically treated patients or their legal representatives; 85 (82.5\%) were returned by the end of August 2015.

The questionnaire included 4 categories: 1) seizure status (Engel classification was used for assessment of treatment outcome ${ }^{14}$ ), 2) the use of AEDs, 3) social activities (employment, school enrollment, driving, and marriage), and 4) satisfaction with the treatment outcome.

Postoperatively, we generally monitored our patients intermittently; they were briefly admitted to our hospital 3 months and again 2 years after surgery for evaluation. Every 3-4 years we evaluated their status using a simple questionnaire or a telephone interview. Discrepancies between their replies and data acquired by prior clinical follow-up were clarified by telephone interview and corrected if necessary. Demographic information (sex, age at surgery), preoperative clinical data (age at seizure onset, seizure frequency, type of seizures, imaging findings, and presumed seizure focus), and postoperative clinical information (e.g., type of surgery, morbidity, pathology, seizure status at the time of admission 2 years after surgery, medications taken) were obtained by chart review.

\section{Patient Demographics and Baseline Characteristics}

As shown in Table 1, the final study population consisted of 85 patients: 59 males and 26 females. Their age at seizure onset ranged from 2 months to 15 years, and their age at the initial surgery ranged from 1 to 15 years.

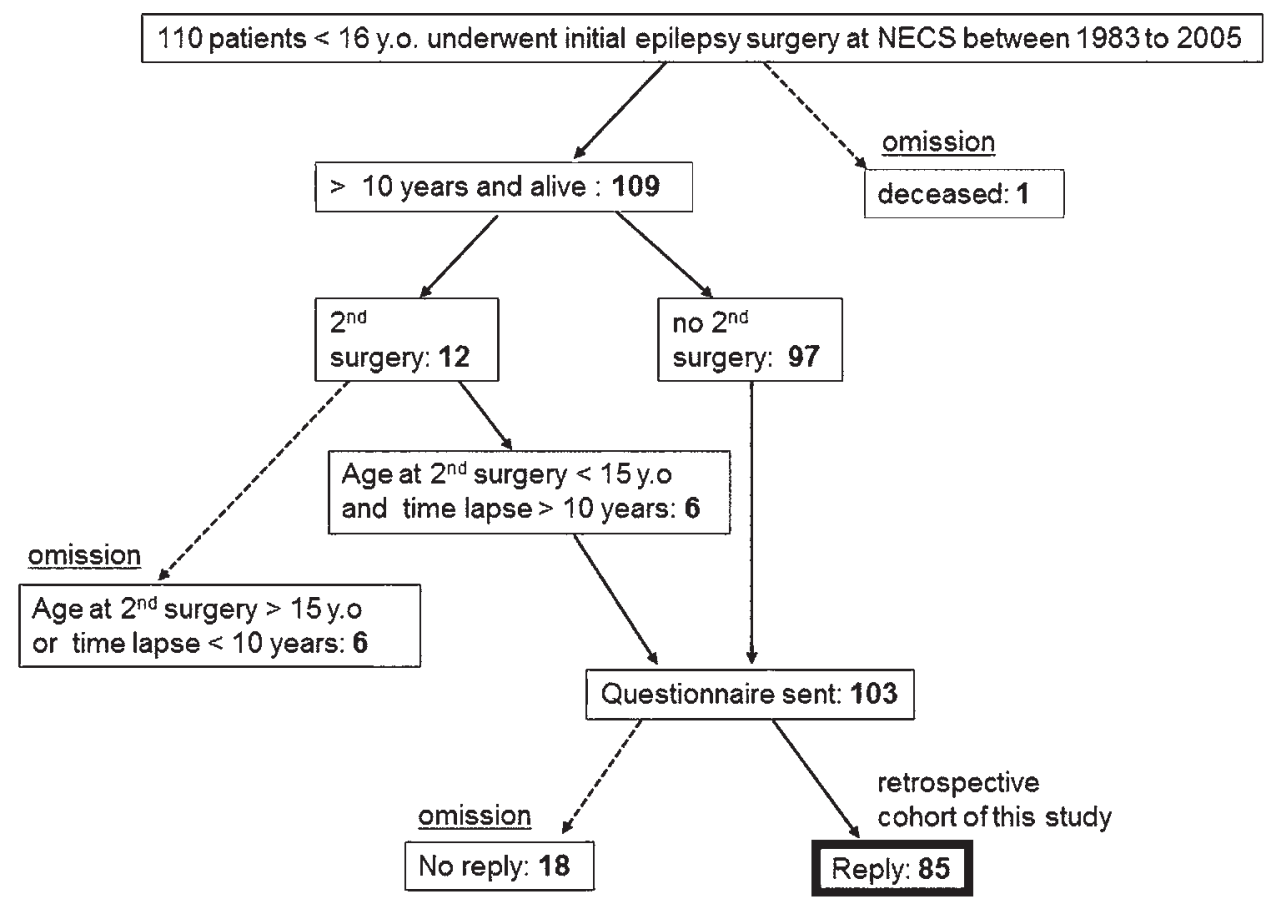

FIG. 1. Flowchart of patient selection. NECS = National Epilepsy Center, Shizuoka; y.o. = years old. 
TABLE 1. Patients demographics

\begin{tabular}{|c|c|}
\hline Parameter & Value* $^{*}$ \\
\hline No. of pts & 85 \\
\hline \multicolumn{2}{|l|}{ Sex } \\
\hline Male & 56 \\
\hline Female & 29 \\
\hline \multicolumn{2}{|l|}{ Age at seizure onset (yrs) } \\
\hline Mean & $3.95 \pm 3.7$ \\
\hline Median & 3 \\
\hline \multicolumn{2}{|c|}{ Duration of epilepsy before op (yrs) } \\
\hline Mean & $5.82 \pm 3.2$ \\
\hline Median & 5 \\
\hline \multicolumn{2}{|l|}{ Seizure frequency } \\
\hline Daily & 49 \\
\hline$>10$ seizures/day & 12 \\
\hline$<10$ seizures/day & 37 \\
\hline Weekly & 24 \\
\hline Monthly & 12 \\
\hline \multicolumn{2}{|l|}{ Age at initial op (yrs) } \\
\hline Mean & $9.78 \pm 4.2$ \\
\hline Median & 11 \\
\hline \multicolumn{2}{|l|}{ Time lapse after op (yrs) } \\
\hline Mean & $15.4 \pm 5.0$ \\
\hline Median & 14 \\
\hline \multicolumn{2}{|c|}{ Age at questionnaire administration (yrs) } \\
\hline Mean & $25.7 \pm 7.1$ \\
\hline Median & 25 \\
\hline
\end{tabular}

The interval between seizure onset and surgery ranged from 3 months to 13 years. In all operations 1 senior author (T.M.) was the primary surgeon. The frequency of epileptic seizures was defined as daily (at least 1 seizure/ day), weekly (at least 1 seizure/week), and monthly (at least 1 seizure/month). Of the 85 patients, 49 (57.6\%) were recorded as having daily seizures (12 suffered $\geq 10$ seizures/day and 37 had $<10$ seizures/day), 24 (28.2\%) as experiencing weekly seizures, and $12(14.1 \%)$ as having monthly seizures (Table 1). The hemispheric laterality of the presumed epileptogenic zone was right in 43 and left in 42 patients.

Preoperative evaluation included long-term video electroencephalography (EEG) (100\%), MRI (98.8\%), CT (75.3\%), intracranial EEG recordings (36.5\%), PET (12.9\%), interictal SPECT (91.8\%), ictal SPECT (38.8\%), and magnetoencephalography (MEG) (81.2\%). All but one of the 85 patients had visible lesions on MRI scans. Until 10 years ago, our institution was a government-run national epilepsy center that for nearly 25 years has been equipped with SPECT (since 1987), MEG (since 1995), and MRI (since 1987) instrumentation. As multiple research projects examined the significance of SPECT and MEG findings with respect to epilepsy surgery, such examinations were performed routinely.
The resection sites were the frontal lobe $(\mathrm{n}=34,40.0 \%)$, temporal lobe $(\mathrm{n}=39,45.9 \%)$, parietal lobe $(\mathrm{n}=1,1.2 \%)$, and occipital lobe $(\mathrm{n}=2,2.4 \%)$; multiple lobes were addressed in 9 patients (10.6\%) (Table 2).

Focal resection or lesionectomy was performed in 42 patients (49.4\%), anterior temporal lobectomy in 29 (34.1\%), selective amygdalohippocampectomy in $10(11.8 \%)$, and hemispherotomy in 4 (4.7\%).

Histologically, the resected lesions were focal cortical dysplasia (FCD) in 37 (43.5\%), developmental/neoplastic lesions in 25 (29.4\%) (dysembryoplastic neuroepithelial tumor in 21, ganglioglioma in 2, meningoangiomatosis in 1, and ependymoma in 1), medial temporal sclerosis (MTS) in $16(18.8 \%)$, and gliosis of unknown cause in 1 $(1.2 \%)$ (Table 2$)$. Four patients $(4.7 \%)$ had a history of encephalitis, and in 2 patients (2.4\%) MRI revealed severe hemispheric atrophy.

There were no surgical deaths. Surgical complications other than visual field defects were recorded in 11 patients (12.9\%); they included expected hemiparesis due to hemispherotomy in 4 patients $(4.7 \%)$ and unexpected hemiparesis in 5 patients $(5.9 \%)$. Of the other 2 patients, one each suffered oculomotor nerve palsy or subdural effusion needing surgical treatment. At their most recent followup, all but one of the 85 patients reported that their morbidities had no strong negative impact on their activities of daily living. The exception was a female who developed left hemiparesis (modified muscle test: 3-4/5) after FCD resection in the right frontal lobe. Her current modified Rankin Scale score is 3.

\section{Statistical Analysis}

We used the Statflex software program (version 6.0, Artech Co.) for statistical analyses. The chi-square and Fisher exact tests were used for independence tests, and multiple regression analysis was performed to identify

TABLE 2. Surgery site and histological diagnosis

\begin{tabular}{lc}
\hline \multicolumn{1}{c}{ Parameter } & No. of Pts \\
\hline Hemispheric laterality in epileptogenicity & \\
\hline Right & 43 \\
\hline Left & 42 \\
\hline Op site & 34 \\
\hline Frontal lobe & 39 \\
\hline Temporal lobe & 1 \\
\hline Parietal lobe & 2 \\
\hline Occipital lobe & 9 \\
\hline Multiple lobes & 37 \\
\hline Background lesion (histological diagnosis) & 25 \\
\hline Focal cortical dysplasia & 16 \\
\hline Developmental/neoplastic lesion* & 1 \\
\hline Medial temporal sclerosis & 4 \\
\hline Gliosis & 2 \\
\hline Postencphalitic & \\
\hline Hemispheric atrophy &
\end{tabular}

* There were 21 dysembryoplastic neuroepithelial tumors, 2 ganglioblastomas, and 1 each of meningioangiomatosis and ependymoma. 
independent factors influencing the seizure outcome. Differences of $p<0.05$ were considered statistically significant.

\section{Ethical Considerations}

This retrospective study was approved by the ethics committee of the National Epilepsy Center, Shizuoka Institute of Epilepsy and Neurological Disorders, Japan. Informed consent specific for this study was waived by the IRB due to the retrospective and noninvasive nature of the investigation in which we used information contained in medical charts and records and obtained by questionnaires, which were anonymized. We certify that this study was carried out in accordance with the Declaration of Helsinki of 1975 as revised in 2000. All data were collected and analyzed under anonymization in an unlinkable fashion to protect patient privacy.

\section{Results}

The interval between the operation and the most recent follow-up, recorded as the date of receipt of the completed questionnaire, ranged from 10 to 30 years, with a median of 14 years. The current patient age ranged from 15 to 43 years (Table 1).

\section{Surgical Outcomes}

The seizure outcome, based on the Engel classification, was Class I in 65 patients (76.5\%; Class Ia 50.6\%, Class Ib $9.4 \%$, Class Ic $8.2 \%$, Class Id $8.2 \%$ ), Class II in $3(3.5 \%)$, Class III in 6 (7.1\%), and Class IV in 11 (12.9\%).

\section{Surgery Site}

Significantly fewer patients in Engel Class I underwent multilobe surgery including hemispherotomy than those undergoing single-lobe surgery $(44.4 \%$ vs $80.3 \%$ [p = 0.0300 , Fisher's exact test) (Table 3). Among single-lobe surgery, the seizure-free rate in temporal lobe surgery was slightly better than in frontal lobe surgery: $84.6 \%$ (33 of 39 ) versus $73.5 \%$ ( 25 of 34 ); however, this failed to show significant statistical difference $(\mathrm{p}=0.6744$, chi-square test).

\section{Pathology Background}

Of the 16 MTS patients, 15 (93.8\%) were in Engel Class I, as were 20 of 25 patients $(80.0 \%)$ with developmental/ neoplastic lesions, and 27 of 37 patients $(73.0 \%)$ with FCD. Among 6 patients with postencephalitic brain damage or diffuse hemispheric atrophy, only $2(33.3 \%)$ were in Engel Class I. The proportion of patients in Engel Class I was significantly lower in patients with a suspected diffuse pathology (postencephalitic brain damage and diffuse hemispheric atrophy) than in patients with a localized pathology (FCD, developmental/neoplastic lesions, MTS, and gliosis in a lobe) $(33.3 \%$ vs $79.7 \%, p=0.0254$, Fisher's exact test).

\section{Side of the Operation}

Surgery was performed in the right hemisphere in 43 patients and in the left hemisphere in 42 patients; 35
TABLE 3. Surgery site and seizure outcome based on Engel class

\begin{tabular}{cccc}
\hline Surgery Site & $\begin{array}{c}\text { No. of } \\
\text { Pts }\end{array}$ & $\begin{array}{c}\text { No. in Engel } \\
\text { Class I (\%) }\end{array}$ & $\begin{array}{c}\text { No. in Engel Classes } \\
\text { II-IV (\%) }\end{array}$ \\
\hline Single lobe & 76 & $61(80.3)^{*}$ & \\
\hline FL & 34 & $25(73.5)$ & $9(26.5)$ \\
\hline TL & 39 & $33(84.6)$ & $6(15.4)$ \\
\hline PL & 1 & $1(100)$ & $0(0)$ \\
\hline OL & 2 & $2(100)$ & $0(0)$ \\
\hline Multiple lobes $†$ & 9 & $4(44.4)$ & $5(55.6)$ \\
\hline Total & 85 & $65(76.5)$ & $20(23.5)$ \\
\hline
\end{tabular}

$\mathrm{FL}=$ frontal lobe $\mathrm{OL}=$ occipital lobe; $\mathrm{PL}=$ parietal lobe; $\mathrm{TL}=$ temporal lobe .

${ }^{*} p=0.0300$ compared with multiple lobes, Fisher's exact test.

$\dagger$ Including diffuse hemisphere lesions.

$(81.4 \%)$ and $30(71.4 \%)$ patients, respectively, were in Engel Class I. The difference was not statistically significant $(\mathrm{p}=0.3155$, Fisher's exact test). Among 39 patients who underwent temporal lobe surgery, all 16 with surgery performed on the right and 17 of 23 (73.9\%) with surgery performed on the left side were in Engel Class I. The difference was not statistically significant $(\mathrm{p}=0.0642$, Fisher's exact test).

\section{Age at Surgery}

There was no relationship between the seizure outcome and patient age at surgery or the interval between epilepsy onset and surgery ( $<5$ or $>5$ years).

\section{Age at Seizure Onset}

Of 28 patients who experienced their first seizure before the age of 2 years, $16(57.1 \%)$ were in Engel Class I, as were 49 of $57(86.0 \%)$ who were older than 2 years at the time of their first epileptic seizure. The difference was statistically significant ( $p=0.0058$, Fisher's exact test).

\section{Seizure Frequency}

As shown in Table 4, only 5 of 12 patients (41.7\%) who suffered 10 or more seizures per day were in Engel Class I. However, 60 of 73 (82.2\%) epileptic patients with a lower seizure frequency were in Class I. The difference was statistically significant ( $p=0.0056$, Fisher's exact test).

Interval Between Seizure Onset and Surgery

In 36 patients the interval between seizure onset and surgery was shorter than 5 years, and in 49 it was 5 years

TABLE 4. Seizure frequency at surgery and seizure outcome (Engel class)

\begin{tabular}{cccc}
\hline $\begin{array}{c}\text { Seizure } \\
\text { Frequency }\end{array}$ & $\begin{array}{c}\text { No. of } \\
\text { Pts }\end{array}$ & $\begin{array}{c}\text { No. in Engel } \\
\text { Class I (\%) }\end{array}$ & $\begin{array}{c}\text { No. in Engel } \\
\text { Classes II-IV (\%) }\end{array}$ \\
\hline$>10 /$ day & 12 & $5(41.7)^{*}$ & $7(58.3)$ \\
\hline$<10 /$ day & 73 & $60(82.2)$ & \\
\hline Daily (1-9/day) & 37 & $27(73.0)$ & $10(27.0)$ \\
\hline Weekly & 24 & $22(91.7)$ & $2(8.3)$ \\
\hline Monthly & 12 & $11(91.7)$ & $1(8.3)$ \\
\hline
\end{tabular}

* $p=0.0056$ compared with less than 10/day, Fisher's exact test. 
or longer. The interval did not significantly affect the seizure-free outcome (Engel Class I) $(69.4 \%$ vs $79.6 \%$, p = 0.3171 , Fisher's exact test).

\section{Follow-Up Duration}

In 46 patients the follow-up ranged from 10 to 14 years; 39 patients underwent follow-up for more than 15 years. Of the former, $80.4 \%$ were in Engel Class I, as were 71.8\% of the latter. The difference was not statistically significant ( $p=0.4435$, Fisher's exact test). The mean follow-up duration was $15.6 \pm 5.2$ years in patients with Engel Class I and $14.8 \pm 3.8$ years in patients in Engel Classes II-IV (p $=0.7797$, Student t-test).

\section{Developmental Quotient}

The preoperative development quotient (DQ) was available for 40 patients; it was below 50 in 19 and above 50 in 21 . Only 9 of 19 patients (47.4\%) with a lower and 17 of $21(81.0 \%)$ with a higher DQ were in Engel Class I. The difference was statistically significant $(\mathrm{p}=0.0457$, Fisher's exact test).

\section{Use of AEDs}

Among the 65 patients in Engel Class I, 29 (44.6\%) stopped and 36 (55.4\%) continued receiving AEDs. Single-drug therapy was administered to 21 patients, 13 took 2 drugs, and 1 patient each was on 3 and 4 AEDs. In 24 (66.7\%) of 36 Engel Class I patients, the drugs were continued to combat vague anxiety of the patient and/or family members; 12 patients (33.3\%) took AEDs on their physician's advice.

\section{Social Participation}

Of the 85 study subjects, 30 (35.3\%) had full-time jobs (25 with regular jobs and 5 with temporary jobs) (Fig. 2), $8(9.4 \%)$ worked part time, $14(16.5 \%)$ were employed in community workshops or vocational centers, 24 (28.2\%) were enrolled in school, 1 was a homemaker, and 4 failed to answer the question regarding employment. Of the 81 responders to this question, 4 (4.9\%) were not engaged in any occupation. Among the 65 Engel Class I patients, 29 (44.6\%) held full-time jobs.

There were 43 patients who were 25 years or older at the time of our survey. Of these, $21(48.8 \%)$ were employed full time, $6(14.0 \%)$ were part-time workers, and $2(4.7 \%)$ were enrolled in vocational schools. The rate of full-time employment in this age group was 55.3\% (21 of 38) in Engel Class I and $0 \%$ (0 of 5) in Class II-IV patients. The difference was statistically significant (Fisher's exact test, $\mathrm{p}=0.0485$ ).

None of the 4 patients who underwent hemispherotomy were employed or enrolled in a regular school; they attended special support schools or community workshops.

Among 59 Engel Class I patients whose age made them eligible for driving (18 years or older), 33 (55.9\%) had a driver's license; 15 of them obtained a license between the age of 18 or 19 years.

In Japan, the minimum age for obtaining a marriage license is 18 years for males and 16 years for females. Of our 85 study subjects, 76 (89.4\%) had reached a marriageable age at the time of our survey (mean current age 27.0 \pm 6.2 years, median 26 years); only 5 patients $(6.6 \%)$ had married, and all of them were in Engel Class I.

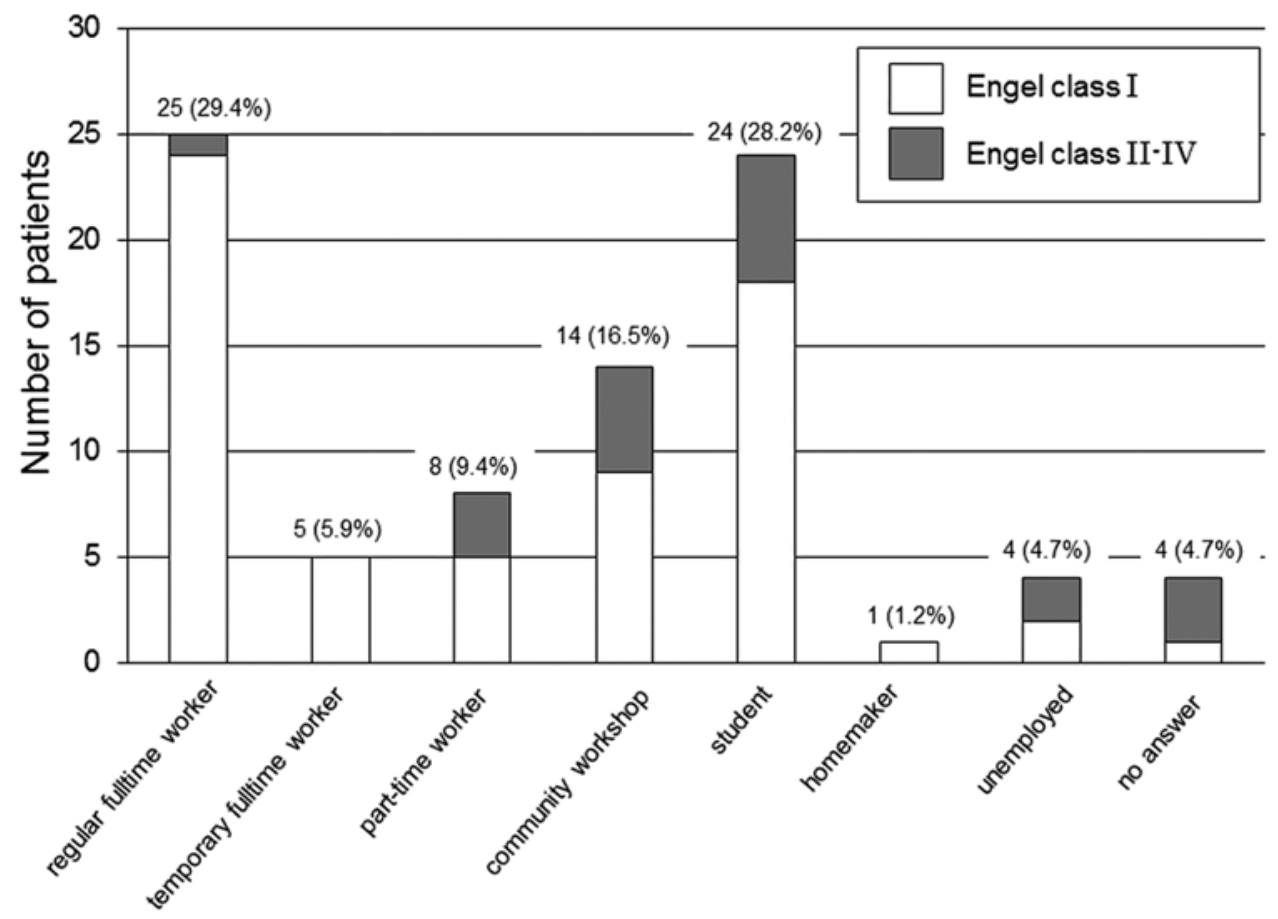

FIG. 2. Employment history at the time of this survey. Only 4 of the 85 responders (4.9\%) had no occupation. Engel Class I patients included an overwhelming majority of full-time workers. 


\section{Degree of Satisfaction With Surgery}

The degree of satisfaction with the epilepsy surgery was recorded as A, very satisfied; B, satisfied but below expectations; $\mathrm{C}$, dissatisfied without regrets; and $\mathrm{D}$, dissatisfied with regrets. Of the 85 patients, 73 responded to this question; of these patients, 58 reported Grade A (79.5\%), 10 Grade B (14.0\%), 3 Grade C (4.1\%), and 2 Grade D (2.7\%) (Fig. 3). Fifty-three of 58 (79.5\%) Grade A patients were in Engel Class I and 5 of the remaining 15 (33.3\%) were in Engel Classes II-IV. The difference was statistically significant ( $\mathrm{p}<0.0001$, Fisher's exact test).

\section{Factors Affecting the Seizure Outcome}

We used multiple regression analysis to identify factors that affected the patients' Engel classification. Class I was coded as 1 , the other classes (dependent variable) as 0 . The laterality of the epileptic foci, the site addressed by surgery, the background lesion(s), the patient age at onset, the interval between seizure onset and surgery, and the seizure frequency were the independent variables. The stepwise variable selection procedure indicated a regression model $(p<0.0001)$. Independent factors leading to a poor seizure outcome were postencephalitic epilepsy (regression coefficient $-0.611, p=0.0022$ ), age younger than 2 years at onset (regression coefficient $-0.223, \mathrm{p}=0.0158$ ), and seizure frequency ( $\geq 10$ /day (regression coefficient -0.351 , $p$ $=0.0052$ ).

\section{Discussion}

\section{Surgical Outcomes}

Seizure control obtained by epilepsy surgery was reported to be comparable in children and adults. . $^{8,56,58,67}$ Among children, $76 \%$ who had undergone temporal lobe surgery and $56 \%$ treated for extratemporal lobe epilepsy were subsequently seizure free. ${ }^{15,16}$ However, the postoperative recurrence of seizures has been reported in children as well as adults. $2,26,38,39,68$ Considering the long life expectancy of children with pharmacoresistant seizures and the progressive decline in their QOL, ${ }^{9,41,50}$ the long-

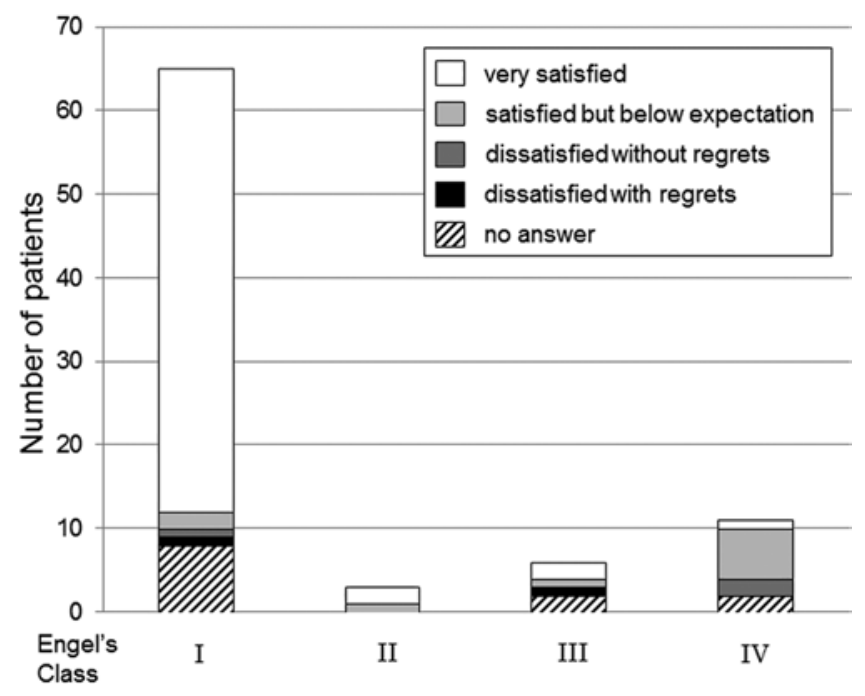

FIG. 3. Degree of satisfaction with the surgical treatment $(n=85)$. term effectiveness of epilepsy surgery must be better understood.

Table 5 is a list of 9 reports of the treatment outcomes in children, including ours, who underwent epilepsy surgery and were monitored for a mean or median of more than 5 years. ${ }^{1,2,19,20,26,28,44,60}$ The rate of patients in Engel Class I at the latest follow-up widely varied from $40 \%$ to $82 \%$, possibly due to differences in the surgical targets, the surgical procedures, and the length of follow-up. The best results were obtained by temporal lobectomy.,26,44

In our series of 85 patients, $65(76.5 \%)$ were in Engel Class I at the latest follow-up. We attribute the good outcome to our strategy of considering pediatric patients with visible lesions on MRI to be surgical candidates. We think that our extensive use of PET, inter- and intraictal SPECT, MEG, and our more frequent use of intracranial EEG recording than in other centers ${ }^{21}$ contributed to the correct identification of the epileptogenic foci. We identified the region responsible for the pathology of intractable epilepsy in $89.4 \%$ of our patients.

\section{Factors Predictive of the Seizure Outcome}

Multivariate analysis revealed the background lesions, the age at seizure onset, and the seizure frequency as independent factors predictive of a good seizure outcome.

Postencephalitic epilepsy, young age at onset ( $<2$ years), and frequent seizures ( $\geq 10$ /day) were factors predictive of a poor seizure outcome, suggesting that widespread and complicated epileptogenicity with underlying diffuse cerebral dysfunction is refractory to resective surgery.

Previously reported predictors of good surgical outcomes in children are unilobar temporal resection, unifocal lesions on MRI, localizing ictal EEG findings, complete lesional resection, an active region on EEG, and the absence of preoperative generalized tonic-clonic seizures. ${ }^{56}$ In patients with temporal lobe epilepsy, factors predictive of better surgical outcomes are right-sided surgery, visible lesions on MRI scans, a history of febrile convulsions, and epileptogenicity due to tumors or cavernous angiomas. ${ }^{2,44}$ No obvious abnormality, a diffuse pathology, and preoperative secondarily generalized seizures were reported as risk factors for postoperative seizure recurrence in patients with temporal lobe epilepsy. ${ }^{16,39}$

A shorter epilepsy duration and a younger age were also reported to be predictive of postoperative seizure freedom in children. ${ }^{10,15,19,67}$ Early resection of the epileptogenic focus, before seizure-generating mechanisms become more complex and spread, may enable better seizure control.

\section{Use of AEDs}

Cure in epileptic patients is defined as seizure freedom without AEDs. ${ }^{5,51}$ Of our 65 Engel Class I patients, 29 (44.6\%) were off and 36 (55.4\%) were on medications. The overall cure rate in our series was $34.1 \%$ (29 of 85).

Others $^{2,5,22}$ have reported cure rates in pediatric patients ranging from $36 \%$ to $54 \%$. The appropriate timing for the discontinuation of AEDs after successful epilepsy surgery remains to be determined. $5,39,51$ In a prospective survey, there was no difference in the seizure relapse rate between patients who continued receiving AEDs and those who reduced the drug dose or stopped receiving AEDs. ${ }^{3}$ Accord- 
TABLE 5. Review outcome of pediatric epilepsy surgery followed up longer than 5 years in mean or median

\begin{tabular}{|c|c|c|c|c|c|}
\hline Authors \& Year & $\begin{array}{l}\text { No. of } \\
\text { Pts }\end{array}$ & $\begin{array}{l}\text { Type of Seizure or } \\
\text { Epilepsy Focus }\end{array}$ & Surgical Procedure & FU Period in Yrs & $\%$ Engel Class I at Latest FU \\
\hline Keene et al., $1998^{29}$ & 63 & NA & Resection & $>2($ mean 7.6$)$ & $50 \%$ \\
\hline Jarrar et al., 2002 & 35 & TLE & Temporal lobectomy & $>15$ & $82 \%$ at $5 \mathrm{yrs} ; 53 \%$ at $15 \mathrm{yrs}$ \\
\hline Hamiwka et al., 2005 & 40 & Cortical malformations & Resection & 10 & $40 \%$ \\
\hline Mittal et al., 2005 & 109 & TLE & Temporal lobectomy & $>5$ (median 11) & $82 \%$ \\
\hline Van Oijen et al., 2006 & 65 & Various & Resection & $>4$ (mean 7.5$)$ & $72 \%$ \\
\hline Benifla et al., 2008 & 42 & TLE & Temporal lobectomy & $>10$ (median 12) & $67 \%$ \\
\hline Aaberg et al., 2012 & 38 & Various & Resection & $>2$ (median 7$)$ & $58 \%$ \\
\hline Hallböök et al., 2013 & 47 & Various & 40 resections, 3 disconnections, 4 other & $>5$ (median 11) & $49 \%$ \\
\hline Present series, 2016 & 85 & Various & Resection & $>10$ (median 14$)$ & $77 \%$ \\
\hline
\end{tabular}

$\mathrm{FU}=$ follow-up; NA = not available; TLE = temporal lobe epilepsy.

ing to another prospective study, the withdrawal of AEDs 3-12 months after successful surgery was safe, and seizure recurrence was easily managed in 258 patients, including those who underwent anterior temporal lobe resection. ${ }^{49}$ In their retrospective survey of 766 children, Boshuisen et al. ${ }^{5}$ found that the early reduction in the AED dose and cessation of AED administration predicted seizure recurrence (hazard ratio $0.94,95 \%$ CI $0.89-1.00 ; p=0.05$ ). However, seizure freedom could be regained by restarting AEDs irrespective of the timing of drug withdrawal. More recently, Boshuisen et al. ${ }^{6}$ suggested that the IQ of children increased after the cessation of AED administration.

Considering the adverse effects of AEDs on neuropsychological functions and the relative ease with which seizure freedom is regained by restarting AEDs, the withdrawal or tapering of AEDs may be a proper choice in patients with 2 years of postoperative seizure freedom. As two-thirds of our Engel Class I patients continued receiving AEDs due to their or family members' ill-defined anxiety, education and consultation might play an important role in facilitating the withdrawal of AEDs.

\section{Social Participation}

Children with epilepsy manifest progressive developmental delays, learning disabilities, and psychiatric and behavioral difficulties that impair social adaptation and their QOL. ${ }^{7,13,31,40,56}$

\section{Employment}

Seizure-free adults with childhood-onset epilepsy were more likely to be employed than epileptic patients still suffering seizures, ${ }^{2,31,46,48,53}$ and seizure freedom after surgery improved their chance of employment and school enrollment. ${ }^{2,11,26,28,29,48,53}$ A Swedish population-based prospective analysis of adult patients who underwent epilepsy surgery reported that favorable seizure outcomes, preoperative employment, and a younger age were independent predictive factors for full-time employment ${ }^{11}$ suggesting that the beneficial effects of seizure freedom on employment argue for early referral for surgery to manage patients with intractable epilepsy.

Very few reports with long-term postoperative follow-up ( $>5$ years) addressed the employment status of epileptic patients. ${ }^{2,26,60}$ Benifla et al. ${ }^{2}$ reported that among
42 patients treated by temporal lobe surgery, 32 (76.2\%) were employed or enrolled in school at the most recent follow-up (median 12 years); 24 of 28 of their Engel Class I patients $(85.7 \%)$ were employed or enrolled in school. Another long-term follow-up study (at least 15 years) ${ }^{26}$ of 32 patients who underwent temporal lobectomy during childhood found that 25 patients $(78.1 \%)$ were gainfully employed, 3 (9.4\%) were homemakers, 1 (3.1\%) had a parttime job, and 3 (9.4\%) were unemployed. A study from the Netherlands showed that 27 of 41 patients $(65.9 \%)$ older than 16 years had a paying job at the most recent followup. In our study population of 85 patients, only 4 (4.7\%) were not engaged in any occupation. However, only 21 $(48.8 \%)$ of 43 patients 25 years or older worked full time; all of these patients were in Engel Class I. Thus, seizure freedom after surgery is essential for epileptic patients to be financially self-supporting. The low rate of full-time workers may be partly influenced by the currently increasing rate of nonregular employment in Japan. According to the 2010 national census, the rate of nonregular employment was $28.4 \%$ in adults between the ages of 25 and 34 years. ${ }^{43}$ Regional employment status might have a greater negative impact on young epileptic patients, even those with good seizure control.

In our series, 8 patients suffered seizure recurrence more than 2 years after surgery; these patients were downgraded from Engel Class I to Classes II-IV. The full-time employment rate in this group was not available. However, 7 patients were upgraded from Engel Classes II-III to Class I; 2 of these patients (28.6\%) were employed full time. Seizure control in adolescence and early adulthood appears more strongly to affect the degree of participation in the workforce than does seizure control 2 years after surgery.

\section{Driving}

In many countries, the ability to drive is a prerequisite for obtaining employment. The rate of drivers among patients who had undergone epilepsy surgery during their childhood appears to be widely varied $(47 \%-81 \%)$ and reflected in their Engel classification. ${ }^{2,26,62}$ In our series, $33(55.9 \%)$ of 59 Engel Class I patients who were eligible for a driver's license had one. The relatively low rate of possessing a driver's license in our Engel Class I pa- 
tients compared with the nonepileptic population in Japan, $80 \%-90 \%$ in their 20 s and 30 s, could be a reflection of patients' and caregivers' prudence and relative narrow area of patients' daily activity.

\section{Marriage}

Patients with childhood-onset epilepsy are reportedly less likely to marry than the general population, even if they have been seizure free without medication for many years or they have been free from neurological deficit. ${ }^{24,25,52,60,62}$

According to a study from the Netherlands, ${ }^{60}$ of 34 patients who had undergone epilepsy surgery in childhood and were older than 18 years at the most recent follow-up, $9(26.5 \%)$ were in long-term relationships. Among 76 of our patients of marriageable age (median 26 years), only $5(6.6 \%)$ were married; all were in Engel Class I. This low rate of marriage among Japanese epileptic patients whose disease was surgically cured reflects social stigma and a secluded lifestyle adopted before treatment. Programs encouraging social participation have been implemented in Japan; they may increase the opportunity for seizurefree individuals to experience family life. Of 25-year-old Japanese males and females, 5.7\% and 9.5\%, respectively, are married; this rate is $34.3 \%$ and $37.1 \%$, respectively, for 29-year-old individuals. ${ }^{42,43}$ Longer follow-up studies of larger cohorts are needed to evaluate the true impact of surgically controlled epilepsy on the marriage rate.

\section{General Satisfaction With Epilepsy Surgery}

There are very few surveys of the satisfaction level of patients or their parents with surgery performed during childhood. According to Benifla et al., ${ }^{2}$ the mean satisfaction level for the 42 patients who had undergone temporal lobectomy early in life was Grade 4 (satisfied). A later survey of patients who had undergone surgery at the same institution, including patients who had undergone extratemporal surgery, showed that the degree of satisfaction was significantly higher in seizure-free patients than in patients who continued to have seizures at the time of the latest follow-up $(\mathrm{p}<0.001) .{ }^{48}$ Keene et al. ${ }^{29}$ who interviewed 63 patients treated by resection for refractory epilepsy before the age of 18 years, also reported a strong positive correlation between seizure control and the degree of satisfaction.

We also found that strong satisfaction with surgery tended to be high (79.5\%) and that its degree was strongly associated with the patient's Engel class at the time of the survey.

\section{Strengths and Limitations of our Study}

After the study by Jarrar et al., ${ }^{26}$ ours offers the secondlongest follow-up of a patient population that is sufficiently large for statistical analysis of the effectiveness of epilepsy surgery in terms of good seizure control, the rate of active social participation, and the level of patient satisfaction.

We acknowledge the inherent weakness of the kind of questionnaire we used. However, the investigators knew the patients and their family members well because the patients were admitted at least 4 times before and after surgery. In addition, discrepancies between responses and data contained in medical records were resolved by telephone interview. As our study was retrospective and questionnaire based, we were unable to perform quantitative assessment of the patients' QOL and cognitive function or of the relationship between these factors and social participation. A prospective longitudinal study of 21 children treated by focal resection and hemispherectomy showed that their QOL scores for self-worth and competence had improved 2 years after the operation. ${ }^{59}$ Retrospective studies also confirmed QOL improvement irrespective of the type of resection. ${ }^{12,18,29}$ On the other hand, Smith et al., ${ }^{55}$ who compared operated and nonoperated children with intractable epilepsy, detected no difference in the preoperative health-related QOL and the QOL assessed 1 year after surgery.

The surgical treatment of epilepsy in childhood and adolescence is not thought to have adverse effects on cognition. ${ }^{32,37,60,63,65}$ In a subset of epileptic patients with impaired intellectual development, the control of seizures by surgery may prevent a cognitive decline. ${ }^{27,33,60}$ A followup survey exceeding 5 years showed that in most children who had an operation, cognitive function developed as expected. ${ }^{19}$

An earlier survey from our institution that included 17 children with an FCD onset before 3 years of age showed that $10(58.8 \%)$ were seizure free in the course of a 3.2-year follow-up. ${ }^{30}$ After surgery, the DQ and IQ were preserved or improved in 14 of the 17 children $(82.4 \%)$ and the rate of progression in their mental age was significantly greater in Engel Class I than Engel Class II-IV patients.

To gain a better understanding of the efficacy of epilepsy surgery with respect to the long-term QOL and of factors that affect the treatment outcome, we are in the process of performing cohort studies that include the quantitative analysis of the QOL and of cognitive function.

\section{Conclusions}

Our survey, administered at least 10 years after treatment, showed that resective epilepsy surgery in childhood yielded seizure freedom in $76.5 \%$ of patients. Their social participation and treatment satisfaction were closely related, with a good seizure outcome. We think that our study provides additional evidence for the effectiveness of surgery in children with pharmacoresistant epilepsy, especially in those with resectable epileptogenic lesions.

\section{References}

1. Aaberg KM, Eriksson AS, Ramm-Pettersen J, Nakken KO: Long-term outcome of resective epilepsy surgery in Norwegian children. Acta Paediatr 101:e557-e560, 2012

2. Benifla M, Rutka JT, Otsubo H, Lamberti-Pasculli M, Elliott I, Sell E, et al: Long-term seizure and social outcomes following temporal lobe surgery for intractable epilepsy during childhood. Epilepsy Res 82:133-138, 2008

3. Berg AT, Vickrey BG, Langfitt JT, Sperling MR, Shinnar S, Bazil C, et al: Reduction of AEDs in postsurgical patients who attain remission. Epilepsia 47:64-71, 2006

4. Berg AT, Vickrey BG, Testa FM, Levy SR, Shinnar S, DiMario F, et al: How long does it take for epilepsy to become intractable? A prospective investigation. Ann Neurol 60:7379, 2006 
5. Boshuisen K, Arzimanoglou A, Cross JH, Uiterwaal CS, Polster T, van Nieuwenhuizen O, et al: Timing of antiepileptic drug withdrawal and long-term seizure outcome after paediatric epilepsy surgery (TimeToStop): a retrospective observational study. Lancet Neurol 11:784-791, 2012

6. Boshuisen K, van Schooneveld MM, Uiterwaal CS, Cross JH, Harrison S, Polster T, et al: Intelligence quotient improves after antiepileptic drug withdrawal following pediatric epilepsy surgery. Ann Neurol 78:104-114, 2015

7. Camfield CS, Camfield PR: Long-term social outcomes for children with epilepsy. Epilepsia 48 (Suppl 9):3-5, 2007

8. Cossu M, Lo Russo G, Francione S, Mai R, Nobili L, Sartori I, et al: Epilepsy surgery in children: results and predictors of outcome on seizures. Epilepsia 49:65-72, 2008

9. Devinsky O, Westbrook L, Cramer J, Glassman M, Perrine $\mathrm{K}$, Camfield C: Risk factors for poor health-related quality of life in adolescents with epilepsy. Epilepsia 40:1715-1720, 1999

10. Duchowny M, Jayakar P, Resnick T, Harvey AS, Alvarez L, Dean P, et al: Epilepsy surgery in the first three years of life. Epilepsia 39:737-743, 1998

11. Edelvik A, Flink R, Malmgren K: Prospective and longitudinal long-term employment outcomes after resective epilepsy surgery. Neurology 85:1482-1490, 2015

12. Elliott IM, Lach L, Smith ML: Adolescent and maternal perspectives of quality of life and neuropsychological status following epilepsy surgery. Epilepsy Behav 1:406-417, 2000

13. Engel J Jr: Surgical treatment for epilepsy: too little, too late? JAMA 300:2548-2550, 2008

14. Engel J Jr, Van Ness PC, Rasmussen TB, Ojemann LM: Outcome with respect to epileptic seizures, in Engel J Jr (ed): Surgical Treatment of the Epilepsies, ed 2. New York: Raven Press, 1993, pp 609-621

15. Englot DJ, Breshears JD, Sun PP, Chang EF, Auguste KI: Seizure outcomes after resective surgery for extra-temporal lobe epilepsy in pediatric patients. J Neurosurg Pediatr 12:126-133, 2013

16. Englot DJ, Rolston JD, Wang DD, Sun PP, Chang EF, Auguste KI: Seizure outcomes after temporal lobectomy in pediatric patients. J Neurosurg Pediatr 12:134-141, 2013

17. Geerts A, Brouwer O, Stroink H, van Donselaar C, Peters B, Peeters E, et al: Onset of intractability and its course over time: The Dutch study of epilepsy in childhood. Epilepsia 53:741-751, 2012

18. Griffiths SY, Sherman EM, Slick DJ, Eyrl K, Connolly MB, Steinbok P: Postsurgical health-related quality of life (HRQOL) in children following hemispherectomy for intractable epilepsy. Epilepsia 48:564-570, 2007

19. Hallböök T, Tideman P, Rosén I, Lundgren J, Tideman E: Epilepsy surgery in children with drug-resistant epilepsy, a long-term follow-up. Acta Neurol Scand 128:414-421, 2013

20. Hamiwka L, Jayakar P, Resnick T, Morrison G, Ragheb J, Dean P, et al: Surgery for epilepsy due to cortical malformations: ten-year follow-up. Epilepsia 46:556-560, 2005

21. Harvey AS, Cross JH, Shinnar S, Mathern GW: Defining the spectrum of international practice in pediatric epilepsy surgery patients. Epilepsia 49:146-155, 2008 (Erratum in Epilepsia 54:1140, 2013)

22. Hemb M, Velasco TR, Parnes MS, Wu JY, Lerner JT, Matsumoto JH, et al: Improved outcomes in pediatric epilepsy surgery: the UCLA experience, 1986-2008. Neurology 74:1768-1775, 2010

23. Huttenlocher PR, Hapke RJ: A follow-up study of intractable seizures in childhood. Ann Neurol 28:699-705, 1990

24. Jacoby A, Baker GA, Steen N, Potts P, Chadwick DW: The clinical course of epilepsy and its psychosocial correlates: findings from a U.K. Community study. Epilepsia 37:148161,1996

25. Jalava M, Sillanpää M: Reproductive activity and offspring health of young adults with childhood-onset epilepsy: a controlled study. Epilepsia 38:532-540, 1997

26. Jarrar RG, Buchhalter JR, Meyer FB, Sharbrough FW, Laws E: Long-term follow-up of temporal lobectomy in children. Neurology 59:1635-1637, 2002

27. Jonas R, Nguyen S, Hu B, Asarnow RF, LoPresti C, Curtiss $\mathrm{S}$, et al: Cerebral hemispherectomy: hospital course, seizure, developmental, language, and motor outcomes. Neurology 62:1712-1721, 2004

28. Keene DL, Loy-English I, Ventureyra ECG: Long-term socioeconomic outcome following surgical intervention in the treatment of refractory epilepsy in childhood and adolescence. Childs Nerv Syst 14:362-365, 1998

29. Keene DL, Loy-English I, Ventureyra ECG: Patient satisfaction with surgical treatment of refractory epilepsy done in childhood and early adolescence. Childs Nerv Syst 14:30 32,1998

30. Kimura N, Takahashi Y, Shigematsu H, Imai K, Ikeda H, Ootani H, et al: Developmental outcome after surgery in focal cortical dysplasia patients with early-onset epilepsy. Epilepsy Res 108:1845-1852, 2014

31. Koponen A, Seppälä U, Eriksson K, Nieminen P, Uutela A, Sillanpää M, et al: Social functioning and psychological wellbeing of 347 young adults with epilepsy only-populationbased, controlled study from Finland. Epilepsia 48:907-912, 2007

32. Kuehn SM, Keene DL, Richards PMP, Ventureyra ECG: Are there changes in intelligence and memory functioning following surgery for the treatment of refractory epilepsy in childhood? Childs Nerv Syst 18:306-310, 2002

33. Lah S: Neuropsychological outcome following focal cortical removal for intractable epilepsy in children. Epilepsy Behav 5:804-817, 2004

34. Larysz D, Larysz P, Mandera M: Evaluation of quality of life and clinical status of children operated on for intractable epilepsy. Childs Nerv Syst 23:91-97, 2007

35. Liang S, Wang S, Zhang J, Ding C, Zhang Z, Fu X, et al: Long-term outcomes of epilepsy surgery in school-aged children with partial epilepsy. Pediatr Neurol 47:284-290, 2012

36. Loddenkemper T, Holland KD, Stanford LD, Kotagal P, Bingaman W, Wyllie E: Developmental outcome after epilepsy surgery in infancy. Pediatrics 119:930-935, 2007

37. Loring DW, Meador KJ: Cognitive side effects of antiepileptic drugs in children. Neurology 62:872-877, 2004

38. McIntosh AM, Averill CA, Kalnins RM, Mitchell LA, Fabinyi GC, Jackson GD, et al: Long-term seizure outcome and risk factors for recurrence after extratemporal epilepsy surgery. Epilepsia 53:970-978, 2012

39. McIntosh AM, Kalnins RM, Mitchell LA, Fabinyi GC, Briellmann RS, Berkovic SF: Temporal lobectomy: long-term seizure outcome, late recurrence and risks for seizure recurrence. Brain 127:2018-2030, 2004

40. Mikati MA, Ataya N, Ferzli J, Kurdi R, El-Banna D, Rahi A, et al: Quality of life after surgery for intractable partial epilepsy in children: a cohort study with controls. Epilepsy Res 90:207-213, 2010

41. Miller V, Palermo TM, Grewe SD: Quality of life in pediatric epilepsy: demographic and disease-related predictors and comparison with healthy controls. Epilepsy Behav 4:36-42, 2003

42. Ministry of Internal Affairs Japan: National Statistics of Employment 2014. (www.stat.go.jp/info/today/097. htm\#shousai) [Accessed January 5, 2017]

43. Ministry of Internal Affairs Japan: Results of National Census 2010. (http://www.stat.go.jp/data/kokusei/2010/ kihon1/pdf/gaiyou1.pdf) [Accessed January 5, 2017]

44. Mittal S, Montes JL, Farmer JP, Rosenblatt B, Dubeau F, Andermann F, et al: Long-term outcome after surgical treatment of temporal lobe epilepsy in children. J Neurosurg 103 (5 Suppl):401-412, 2005 
45. Mohammed HS, Kaufman CB, Limbrick DD, Steger-May K, Grubb RL Jr, Rothman SM, et al: Impact of epilepsy surgery on seizure control and quality of life: a 26 -year follow-up study. Epilepsia 53:712-720, 2012

46. Okuma T, Kumashiro H: Natural history and prognosis of epilepsy: report of a multi-institutional study in Japan. The group for the study of prognosis of epilepsy in Japan. Epilepsia 22:35-53, 1981

47. Pestana Knight EM, Schiltz NK, Bakaki PM, Koroukian SM, Lhatoo SD, Kaiboriboon K: Increasing utilization of pediatric epilepsy surgery in the United States between 1997 and 2009. Epilepsia 56:375-381, 2015

48. Puka K, Smith ML: Where are they now? Psychosocial, educational, and vocational outcomes after epilepsy surgery in childhood. Epilepsia 57:574-581, 2016

49. Rathore C, Panda S, Sarma PS, Radhakrishnan K: How safe is it to withdraw antiepileptic drugs following successful surgery for mesial temporal lobe epilepsy? Epilepsia 52:627635, 2011

50. Sabaz M, Cairns DR, Lawson JA, Bleasel AF, Bye AM: The health-related quality of life of children with refractory epilepsy: a comparison of those with and without intellectual disability. Epilepsia 42:621-628, 2001

51. Schmidt D, Baumgartner C, Löscher W: Seizure recurrence after planned discontinuation of antiepileptic drugs in seizure-free patients after epilepsy surgery: a review of current clinical experience. Epilepsia 45:179-186, 2004

52. Sillanpää M, Jalava M, Kaleva O, Shinnar S: Long-term prognosis of seizures with onset in childhood. N Engl J Med 338:1715-1722, 1998

53. Sillanpää M, Schmidt D: Long-term employment of adults with childhood-onset epilepsy: a prospective populationbased study. Epilepsia 51:1053-1060, 2010

54. Sillanpää M, Schmidt D: Natural history of treated childhood-onset epilepsy: prospective, long-term population-based study. Brain 129:617-624, 2006

55. Smith ML, Elliott IM, Lach L: Cognitive, psychosocial, and family function one year after pediatric epilepsy surgery. Epilepsia 45:650-660, 2004

56. Spencer S, Huh L: Outcomes of epilepsy surgery in adults and children. Lancet Neurol 7:525-537, 2008

57. Téllez-Zenteno JF, Dhar R, Wiebe S: Long-term seizure outcomes following epilepsy surgery: a systematic review and meta-analysis. Brain 128:1188-1198, 2005

58. Terra-Bustamante VC, Inuzuca LM, Fernandes RM, Funayama S, Escorsi-Rosset S, Wichert-Ana L, et al: Temporal lobe surgery in children and adolescents: clinical characteristics and post-surgical outcome. Seizure 14:274-281, 2005

59. van Empelen R, Jennekens-Schinkel A, van Rijen PC, Helders PJ, van Nieuwenhuizen O: Health-related quality of life and self-perceived competence of children assessed before and up to two years after epilepsy surgery. Epilepsia 46:258271,2005

60. Van Oijen M, De Waal H, Van Rijen PC, Jennekens-Schinkel A, van Huffelen AC, Van Nieuwenhuizen O: Resective epilepsy surgery in childhood: the Dutch experience 1992-2002. Eur J Paediatr Neurol 10:114-123, 2006

61. Vasconcellos E, Wyllie E, Sullivan S, Stanford L, Bulacio J, Kotagal P, et al: Mental retardation in pediatric candidates for epilepsy surgery: the role of early seizure onset. Epilepsia 42:268-274, 2001
62. Wakamoto H, Nagao H, Hayashi M, Morimoto T: Long-term medical, educational, and social prognoses of childhoodonset epilepsy: a population-based study in a rural district of Japan. Brain Dev 22:246-255, 2000

63. Westerveld M, Sass KJ, Chelune GJ, Hermann BP, Barr WB, Loring DW, et al: Temporal lobectomy in children: cognitive outcome. J Neurosurg 92:24-30, 2000

64. Williams J, Griebel ML, Sharp GB, Boop FA: Cognition and behavior after temporal lobectomy in pediatric patients with intractable epilepsy. Pediatr Neurol 19:189-194, 1998

65. Wirrell EC: Predicting pharmacoresistance in pediatric epilepsy. Epilepsia 54 (2 Suppl 2):19-22, 2013

66. Wurm G, Ringler H, Knogler F, Schnizer M: Evaluation of neuronavigation in lesional and non-lesional epilepsy surgery. Comput Aided Surg 8:204-214, 2003

67. Wyllie E, Comair YG, Kotagal P, Bulacio J, Bingaman W, Ruggieri P: Seizure outcome after epilepsy surgery in children and adolescents. Ann Neurol 44:740-748, 1998

68. Yoon HH, Kwon HL, Mattson RH, Spencer DD, Spencer SS: Long-term seizure outcome in patients initially seizure-free after resective epilepsy surgery. Neurology 61:445-450, 2003

\section{Disclosures}

The authors report no conflict of interest concerning the materials or methods used in this study or the findings specified in this paper.

\section{Author Contributions}

Conception and design: Hanaya, Matsuda, Arita. Acquisition of data: Hosoyama, Matsuda, Mihara, Usui, Baba, Tottori, Kashida. Analysis and interpretation of data: Hanaya, Hosoyama, Matsuda, Otsubo, Hirano, Arita. Drafting the article: Hosoyama. Critically revising the article: Hanaya, Hosoyama, Usui, Otsubo, Iida, Arita. Reviewed submitted version of manuscript: Hanaya, Hosoyama, Matsuda, Mihara, Usui, Otsubo, Kashida, Iida, Hirano, Arita. Approved the final version of the manuscript on behalf of all authors: Hanaya. Statistical analysis: Hirano. Administrative/ technical/material support: Matsuda, Baba, Inoue, Tottori. Study supervision: Hanaya, Mihara, Inoue, Arita.

\section{Supplemental Information}

\section{Online-Only Content}

Supplemental material is available with the online version of the article.

Questionnaire. https://thejns.org/doi/suppl/10.3171/2016.12. PEDS16197.

\section{Previous Presentations}

Portions of this work were presented in abstract form at the 39th annual meeting of the Epilepsy Surgery Society of Japan, Tokyo, Japan, January 22, 2016.

\section{Correspondence}

Ryosuke Hanaya, Department of Neurosurgery, Graduate School of Medical and Dental Sciences, Kagoshima University, 8-35-1 Sakuragaoka, Kagoshima 890-8520, Japan. email: hanaya@m2. kufm.kagoshima-u.ac.jp. 